\title{
A viagem em Ruy Duarte de Carvalho
}

\author{
MARTA LANÇA \\ Jornalista e pesquisadora
}

esmedida e Terceira metade, os últimos livros publicados de Ruy Duarte de Carvalho, pautam uma viragem na obra do autor angolano. A uma vida em Angola de dedicação absoluta ao conhecimento profundo desta terra e suas gentes, incidindo nos pescadores da costa de Luanda e nos pastores do sul, ampliavase então o âmbito geográfico das suas pesquisas, e as reflexões investiam num carácter programático: encarar o processo da expansão ocidental em todas as margens atlânticas e os seus efeitos de incidência colateral. Embora focalizasse sempre com maior incidência as questões angolanas, passaram a figurar também o Brasil e outras partes da América, a África do Sul e toda a África ocidental e austral. O eixo atlântico preenchia assim a sua experiência, informação e imaginário, "a triangulação própria pessoal, histórica e especulativa, com uma costa de África a servir de tabela a todos os lances de movimentação e o estimulante insólito de uma improvável ilha de Santa Helena excêntrica e centrada, produto da expansão mas quase alheia à mesma", haveria de explicar, motivado para a escrita de Paisagens efémeras, um livro dramaticamente inacabado.

Andava o Ruy Duarte entusiasmado com projectos curiosos quando partiu. Um deles era uma provocadora proposta neo-animista que subentendia a vontade de criar um movimento que fizesse convergir várias procuras, de académicos, artistas e viajantes. Cada um com o seu contributo (inventário de teses, utopias e formas de organização não devedoras desta economia do crescente) intentaria uma linha (do) comum, que combatesse os lugares de eleição e de privilégio para certos homens e grupos de pessoas e questionasse os impasses do paradigma humanista, procurando resistências ao processo de ocidentalização em curso, à ideia homogeneizante, tão antiga como perigosa, do progresso como salvação da humanidade. 


\section{Viagens nas minhas terras}

A vida inteira viajante, Ruy Duarte cultivava da viagem o arrebatamento e emoção, atravessando, gerindo, procurando as proximidades e diferenças. As viagens eram, mais do que inspiradoras, necessárias, para a pulsação e temperatura da escrita, pois "só sabemos o que lá vamos buscar e encontrar ao ir. Eram viagens não celebratórias da mobilidade, tal como existe impressa nos tempos que correm, em que de Nova Iorque a Pequim passando por Cabo Verde, mastigamos o globo indiferenciadamente. Nem de ilustração de teses ou, na pior das hipóteses, fundamentalismos. Para o Ruy, a mobilidade predispunha-se ao acontecimento, à alegria da experiência e até ao contágio da expressão (em Desmedida sente-se a fala começar a abrasileirar-se, numa simbiose formosa com a coloquialidade angolana e a formalidade portuguesa). É que "tem viagens e tem fugas" e a viagem era um programa, exigindo preparação, abundantes leituras prévias sobre o contextos dos territórios a percorrer, muita observação e uma metodológica escrita de notas durante a viagem, para fixar o que lhe haveria de dar a pensar depois na aventura dos livros.

A essa procura se dedicou pela vida inteira, em livros, filmes, palestras e histórias de contar ao Paulino e ao leitor cúmplice: trazer notícia de como se vive do lado de lá, e como se sobrepõem certos contextos e se desenrolaram os dramas humanos, nas suas tais obsessões geográficas.

Com essa atitude, o Ruy descreveu os pastores ao mundo e o mundo aos pastores.

\section{O Brasil de Desmedida}

"Vim cá e viajei experimentando sempre um sentimento de filho pródigo ciente daquilo que enquanto pessoa deve ao Brasil pelo que desde muito cedo na vida o Brasil the deu a ler, a ouvir, a aprender, a ver e a imaginar", escreveria Ruy Duarte no fim de Desmedida. Para a escrita deste livro, que convoca vários géneros e linguagens, o autor quis descobrir que Brasil seu era esse. Para tal, fez viagens preparatórias ao alto, baixo e médio rio São Francisco, do qual começa por falar "a duas senhoras paulistanas, sentado à mesa delas numa soberba fazenda de café". Explorar o rio S. Francisco afigura-se um trabalho 
de desconstruir o palimpsesto do país e de si próprio: "tentar apreender os seus passados para ver se consigo situar-me nos seus presentes", explorar o S. Francisco vindo ele de Angola "na condição que é a minha e dar-me à ousadia muito pessoal, íntima às vezes, de tentar explicar-me pesando, fundamentando, acrescentando, as minhas percepções do Brasil e do que o Brasil me dá a ver, a ler, a curtir, a abominar do Brasil, do mundo e de mim mesmo" (p 150). É esta dimensão afectiva de "um Brasil que mexe comigo desde que me sei gente" (p. 203) que nos situa, também, no universo do diário de viagem, na subjectividade da percepção.

Por essas águas de São Francisco já tinham andado "bandeirantes e bandidos, escritores e aventureiros", o que deu em várias literaturas (e um Richard Burton, "o explorador aventureiro por excelência", por volta de 1867). Nele vamos desaguando no Brasil e suas figuras, das paisagens naturais às literárias, dos episódios históricos à confidência. Os jagunços implicados nos destinos dos sertões, homens de guerra, que não podem trair a palavra dada. O saque de Januária, o mundo rural da primeira república brasileira, o coronelismo brasileiro como sistema, a origem quilombeira (os negros trazidos para o Brasil ou já ali nascidos, mas rebeldes, terão inventado uma escrita secreta?), percorrendo mitos que tantos "ilustres cientistas, curiosos e artistas ávidos de Brasil e prontos a projectá-lo, com uma glória e com um brilho que se mantém até hoje, nas distinguidas aleias do tão contente de si mesmo saber ocidental".

É que Ruy Duarte não abdica deste jogo de espelhos que é essa imagem de si próprio enredada na dos outros. Pois a "aventura, exaltação produz muita informação e muita efabulação e pesa muito na configuração dos brasileiros sobre si mesmos". E nisso, há outro paralelo entre a percepção de África e do Brasil por estrangeiros que tanto "peso" tiveram nessa formação de identidade.

Detém-se então no Brasil enquanto caso de estudo na "produção social do inédito", onde tantos se pasmaram "diante do inédito, da anarquia e do escândalo da exuberância da flora brasileira" e de outras questões, tendo sido o deslumbramento a enriquecer (e provavelmente enviesar) as investidas científicas (e românticas) dos exploradores e observadores do século XIX e demais. É que "o Brasil para quem vem de fora em condições de dar conta do que se desenrola à frente, oferece de espectáculo, de estímulo e de espanto. Há mais de quinhentos anos que o mundo se detém a interrogar-se sobre o Brasil e a arriscar vir ver quando as condições o permitem” (p. 165). 
Percorre a elaboração literária e intelectual do mulato como tipo brasileiro, o "brasileiro típico", o mulato do Guimarães: "um brasileiro com uma pinta de sangue africano ou alguma coisa de africano na formação da sua pessoa, polido, acolhedor e amável" (p. 192), as regras da cordialidade tão defendida por pensadores da identidade brasileira até chegar ao "património inestimável que é o jeitinho brasileiro".

\section{As coisas estão ligadas}

Mas este Brasil e suas representações não estão isolados. O autor transporta as suas questões de um universo para o outro, com "dificuldade em sacudir as questões que eram as que trazia comigo quando cheguei ao Brasil". Tinha ido à Cidade do Cabo antes, e lá também a complexa formação histórica e cultural se coloca. E quando, a meio das viagens no nordeste brasileiro, regressa a Luanda, ao contar sobre o Brasil ao lado de cá angolano, faz um longo apanhado da história da expansão ultramarina. E até lhe "ocorre congeminar um manual dos passados de Angola para uso de pastores e de analfabetos". E começa a falar do ouro e prata que atraíram os primeiros brancos às feiras, controlados por poderes africanos, as expansões determinadas por déficite de cereais, o início dos pagamentos em escravos e os cavalos que valiam mais do que 20 pessoas, as plantações de açúcar e as travessias no atlântico em cem anos de navegação que puseram a terra inteira ao alcance da Europa de então, o comércio globalizado com os holandeses a tentarem apanhar a onda dos portugueses e espanhóis e as quezílias que daí advieram. E por aí afora, há de explicar os processos das independências brasileira e angolana e se havia indígenas a combater por elas, e chega até aos impasses das democracias actuais. Terrenos muito minados, mas sempre memórias colectivas a serem revistas para não se tornarem mitos obtusos.

\section{Estamos é juntos}

A ligação Angola - Brasil (e inevitavelmente Portugal) é trabalhada neste livro no sentido em que, apesar de passados e configurações distintas, não dá 
para compreender uns sem os outros. "Existimos todos hoje na decorrência de uma colonização que foi dando sumiço àqueles que de maneira como viviam não tinham maneira de resistir, servimo-nos da mesma língua oficial, invocamos lusofonias de hoje que já foram lusotropicalismos antes, somos todos do hemisfério sul, com a cor geopolítica comum que isso comporta, e temos negócios correntes, estamos vivendo tempos comuns e tempos diversos do mesmo processo universal, global. Nós estamos é juntos no vaivém das balsas".

O autor relembra que a ligação se justifica no que já existe e nas relações a fortalecer:

Na dobra destes meus trânsitos e tudo, é a circunstância, dada abundante a comprovar in locco, na crista da onda globalizante produzida pela expansão ocidental ainda e sempre em curso, e que os dois países só teriam vantagem em intensificar toda a ordem de relações no âmbito desse eixo sul sul que finalmente se impõe ao mundo branco que o produziu e agora tem. E que Angola, parceiro privilegiado dos dois pelas vias da vizinhança ou da língua, ou da história e das imperiosas e inarredáveis geopolíticas oceânicas. (p. 149)

\section{Uma forma única de contar}

Neste livro, além da abordagem histórica, cronista e viajante, os embalos poéticos fazem-se sentir, também eles ligados à poética e emoção da viagem. São surpreendentes rasgos como "e vi mulheres carnívoras, necessitantes de nervo e luz solar de macho, duráveis, girantes em torno do sol”. (p 129) Ou o momento em que, na Chapada Gaúcha, dá encontro com o sertão num

sorriso de menina que veio vindo, vendendo flores artificiais, rasgado aberto na claridade crua de uma porção azul e aberto. E da menina o porte, ainda mal deixava adivinhar a velocidade, só, de um tempo a expandir-se em movimento e graça, projéctil de energia de um corpo. Era um sorriso de criança só. Mas para mim era um absoluto sorriso, inventado mineiro num rosto de Octacília à espera de Riobaldo (p. 127) 
A projecção da escrita dos outros na sua fá-lo prosseguir no fascínio de por figuras geniais que, também na errância e nas vidas arriscadas, trouxeram notícias de coisas extraordinárias - E lá, tem é o quê?. Visitou o Brasil a fundo na companhia de Euclides da Cunha, Guimarães Rosa, Richard Burton, Cendrars, Teodoro Sampaio e Saint-Hilaire. Com Joseph Conrad, remexeu nas feridas de África.

Ruy Duarte de Carvalho fundou, junto com o contar dos outros, escritores, poetas, viajantes que se encontram numa mesma inquietação, nas paisagens da vida e nas paisagens literárias, o seu contar único, por oposição à escrita "sopa de letras liquidificada pelas tecnologias de mediatização" ou a "propostas literárias de talentos jornalísticos assim assim”. Uma escrita generosa e rigorosa que ajudou sempre à tradução das diferenças de ordem económica, cultural, sexual, ofícios, luz na paisagem, animais (por vezes mais interessantes que o tão prematuro animal homem), poderes e contra-poderes, trazendo as referências literárias mais estimulantes, a ousadia dos que abrem caminhos, a poética da terra, a cadência da oralidade e o rigor científico na descrição.

$\mathrm{O}$ acto de ir lá registar obedecia à necessidade de estabelecer uma horizontalidade com os vários factores e povos e dar visibilidade, por exemplo, no momento fundador da Independência de Angola, aos outros angolanos, que pudessem até não corresponder à figura do que devia ser o cidadão angolano. Tal como quando trouxe à discussão as contradições das fronteiras herdadas do colonialismo, que dividiam outras nações que continuam, nas suas práticas, alheias às mesmas. Eram preocupações que previam, com apreensão apesar do entusiasmo, alguma negligência futura.

Tal como o seu cinema recorria à literatura, os livros adquirem, da linguagem cinematográfica e da experiência da viagem, o aprendizado de saber olhar (e lá estar) para saber descrever. É um ofício que se vai apurando, sem nunca deixar nas reticências a adivinhação do que falta. É a "formulação cinematográfica da própria ideia", a ideia a funcionar por imagem, diz o Ruy em Desmedida: "nunca estive em nenhum lugar, e em qualquer tempo, mesmo de uma maneira geral na vida, se não como fosse para voltar depois e rodar um filme”.

As imagens estão na base da empatia com os lugares e com a descrição de lugares, como o momento de encontro com a escrita do Guimarães Rosa (o Grande Sertão, numa tabacaria da Gabela, no Kwanza Sul), um tipo de ficção e escrita adequada à sua "geografia e substância humana". Ruy Duarte mostra 
uma postura reverencial a esse génio brasileiro quando percebeu que jamais "lhe atingiria a tentação de querer escrever assim, são coisas para quem já nasce ensinado ou aprende depois por uma via que haveria de eleger-me a mim. Pelo que de todo, sendo simples mortal, o melhor também é não ler Guimarães Rosa, enquanto escrevo" (p. 107).

Agora que o Ruy já não se dá ao trabalho de viver, que "não pode deixar de ser, de facto, muito perigoso", erudito e poeta nas formulações, figura rara contra a indiferenciação do mundo, o que há a fazer é ler a sua obra de constante aprendizagem. 